\title{
Practice and Reflection on Improving the Management of Teacher Training Base: Experience from Changshu Institute of Technology
}

\author{
Xiao-Jiao SONG ${ }^{1, a,{ }^{*}}$ and Shuai YANG $^{2, b}$ \\ ${ }^{1}$ School of Continuing Education, Changshu Institute of Technology, Suzhou, China \\ ${ }^{2}$ School of Econimics and Management, Changshu Institute of Technology, Suzhou, China \\ A songxiaojia0615@163.com, ${ }^{\text {b}} 1393655123 @ 163 . c o m$ \\ *Corresponding author
}

Keywords: Teacher Training Base, Teacher Training Management, Management Specialization

\begin{abstract}
The teacher training base shoulders the important task of hosting various types of teacher training at all levels. The effective development of teacher training is dependent on the professionalization of training base management. Further improving the management level of the teacher training base is not only to meet the increasingly heavy task of teacher training, but also to meet the needs of the development and development of the base itself, and it is more related to the implementation effect and quality of the teacher training program.
\end{abstract}

\section{Introduction}

President Xi Jinping pointed out at the 19th Party Congress that "we must give priority to the development of education." At present, the problem of unbalanced development of education in all regions of China still exists. The quality of teachers and the level of education in remote areas such as the central and western regions still have a large gap compared with developed regions.Therefore,the scale of continuing education for primary and secondary school teachers and vocational college teachers continues to expand, and financial support for continuing education for teachers in the central and western regions is also greater.For example, the Ministry of Education and the Ministry of Finance have implemented the national-level training plan for primary and secondary school teachers since 2010 to improve the overall quality of teachers in primary and secondary schools, especially in rural areas.Since 2011, in order to promote and strengthen the construction of teachers in vocational colleges and promote the scientific development of vocational education, the Ministry of Education and the Ministry of Finance have successively implemented plans to improve the quality of teachers in vocational schools. There are also various types of provincial backbone (specialized) teacher training, local special training, etc.

Changshu Institute of Technology is a provincial undergraduate institution. It was originally a Suzhou Teacher's College that began in 1958.Since 2012, it actively responded to the call of the national, provincial and municipal authorities to apply for and undertake the tasks of primary and secondary school teacher training and vocational college teacher training at all levels within and outside Jiangsu province.Due to the lack of system and experience at the beginning, we have also gone through some detours.After years of practice and exploration, a complete set of teacher training management system has basically been formed and teacher training has begun to take shape.The continuing education of Changshu Institute of Technology implements two levels of management. The School of Continuing Education assumes the management function of teacher training on behalf of the school. Each secondary school is the main unit for the implementation of teacher training. With regard to the scale of training, from 2012 to now, it has undertaken more than 140 tasks for teachers of all levels and trained more than 12,900 teachers. It has contributed to boost professional development of teachers and improve the quality of teachers within and outside Jiangsu province.In particular, the task of training primary and secondary school teachers, principals and vocational college teachers in Guangxi Province since the beginning of the year has been in place for five years. It has made great 
achievements in the construction of teachers in the central and western regions and the exchange and development of teachers in the two provinces.

\section{Development Proposals}

The effective development of teacher training is inseparable from the specialization of training base management. In order to better meet the increasingly heavy task of teacher training, ensure the effectiveness and quality of the teacher training program, and improve the management level of the teacher training base, the following three aspects should be adopted.

\section{Strengthen System Construction and Team Management}

\section{Set up a Dedicated Training Management Team}

At present, there are about two types of teacher training management models for colleges and universities. One is the establishment of an independent teacher education and training department(e.g.school of continuing education). The department has a full-time training management team and specialized and part-time training teachers. The organizational planning and implementation of teacher training are all completed by the school of continuing education ; one is two-level management. The teacher education and training department, as a functional department, arranges and manages the training work in an integrated manner, and jointly undertakes and implements the teacher training program with related secondary schools.Changshu Institute of Technology is the second management model.The school of continuing education currently has 4 full-time training management personnel, who are responsible for the organization, planning, guidance, management, coordination, and service functions.Each secondary school is under the responsibility of the vice president in charge of training. Each training project is staffed with a special project leader and head teacher, responsible for the formulation and writing of training programs, the organization of experts and teachers, the specific implementation of the project, and the management of training classes.The two modes have their own advantages and disadvantages. The first mode is more professional in management. Due to the large number of departments and complete personnel, it is conducive to the large-scale and extensive development of various types of teacher training;the second mode is easy to mobilize the enthusiasm of the secondary school and give full play to the advantages of disciplines and specialties.No matter which model, the teacher training base should have a special training management department, a sound system, and a clear division of personnel.In order to make the training of teachers more standardized and institutionalized, a leadership team for training should be established at the school level, and there should be a dedicated manager in charge of the training.At the same time, as the implementation of the training of teachers also involves logistics, security, finance, information and so on, the Department of logistic support, security, finance office and information office should also be included in the leading group of the training work. The leading group exercises the functions of planning, decision-making, guidance, deliberation, evaluation and quality control in the training program, regularly researches the problems in the training, and makes policy adjustments in time.

\section{Develop a Strict Training Management System and Implement Humane Management}

In terms of teaching management, teachers with rich management experience should be selected to act as headteachers and be responsible for the daily learning and life management and coordination of trainees;establish a strict attendance system, adhere to the daily attendance of each training class;set up a class committee to be responsible for the management of the training class;according to the number of trainees, a number of learning groups can be established, and team leaders can be set up to assist in organizing group discussions, exchanges and visits;according to the different training programs, arrange the trainees to submit lecture notes, observations, teaching design, micro-curricular production, training summary, etc.;qualified students are awarded a certificate of completion, and 
outstanding students are awarded outstanding student certificates.In terms of file management, all lectures are recorded throughout the video, and observations are conducted for photography or videotaping; after the training, the trainees were organized to conduct a project satisfaction survey. All training related materials are archived by the school teacher training department;in terms of logistical support, accommodation, catering, and security systems are sound and strictly in accordance with standards.Although the management system is rigorous, humanized management must be implemented in the implementation process so that the combination of institutionalization and humanization can maximize students’ learning enthusiasm.

\section{Pay Attention to the Formulation and Implementation of the Plan and Provide Quality Training}

\section{In-depth and Detailed Organizational Pre-study}

In order for the training course to be as close as possible to the actual work of the teacher, the content of the training should be targeted. Therefore, the analysis of the training needs prior to the development of the training program is particularly important.There are two main ways to conduct demand research on teacher training. The first one is questionnaires, including on-site questionnaires and online questionnaires. Data analysis is then followed, focusing on scientific and normative analysis of training needs analysis.The second is on-the-spot investigations, in-depth delivery of training units and front-line teachers and academic leaders to hold discussions, understand the teachers' confusion and needs in practical work, write research reports, and provide basis for the development of training programs and training work.For example, before Changshu Institute of Technology launched the implementation of the provincial training program for higher vocational colleges in Jiangsu province in 2017, it visited and investigated several vocational colleges in the province, and issued an online questionnaire. The combination of the two research methods was sufficient. Data and training needs surveys have laid a solid foundation for improving the pertinence and effectiveness of training and are an important part of successful training.

\section{Clear Training Objectives and Optimize Project Plans}

The training base should have an in-depth understanding of the national, provincial, and municipal teacher training policies, and pay attention to the most cutting-edge trends in the development of teacher training. The training topics should meet the spirit of education and teaching reform and the actual needs of teachers' professional development. The development of training goals must be reflected in four ways. That is, it embodies the actual work of the trainees, embodies the advanced concepts and theoretical frontiers, embodies the knowledge development and the improvement of education and teaching skills, and reflects the construction of teachers' ethics and professional growth of teachers.The design of the training course should be combined with the results of the previous training needs research to highlight the pertinence and effectiveness of the curriculum and focus on the combination of theory and practice. The proportion of practical courses must meet or exceed the curriculum setting standards stipulated by the higher authorities.For example, in 2017, Changshu Institute of Technology hosted the Guangxi National Training Project - Township Center Principal Training. The goal is to improve the ability of township school headmasters to co-ordinate and select school paths. Through 5 days of intensive training and 10 days of practice, the principals of the township and township schools participating in the training have updated their schooling concepts and improved their ability to administer schools, making the principals of township and township centers become leaders in the reform and development of basic education in Guangxi.

\section{Build a High-level Team of Experts}

The number of candidates for training teachers should be able to fully meet the teaching needs, there are alternative teacher resources, and the structure of teachers is reasonable. The expert team must have education management experts from institutions of higher education, educational and scientific research institutions, education administration departments, and teacher training 
professional institutions. , teacher training research experts, but also from the front-line of the outstanding typical teachers, principals, etc.Among them, the proportion of outstanding teachers, principals and teaching and research staff is not less than 50\%. At the same time, in order to better understand the relevant national, provincial, and municipal training policies, priority should be given to the selection of "national training" and "provincial training" expert database members as members of the training expert team to achieve first-line teachers, universities, and teaching and research institutions. The theory and practice experts of the education administrative department and the teacher training institution are combined in a rational structure with complementary advantages.

\section{Focus on the Diversity of Training Form}

In the training process, we must consider the actual needs of trainees, be problem-oriented, and use case as the carrier to highlight interactive teaching. Through the combination of special lectures and observation training, the combination of intensive learning and exchange seminars, case demonstration and commentary, and experience reflection, we provide multi-dimensional training in content-rich and three-dimensional cross-sections to improve the relevance and effectiveness of training.For example, in the course of training for senior management of middle management cadres in vocational colleges in Guangxi in 2017, taking into account the actual needs of the middle management cadres, we took two days of intensive training, one-on-one posts for 13 days, and highlighted the training of middle level cadres' practical ability.In the intensive training stage, case-based, scenario-based, and discussion-based teaching methods were applied to enhance the theoretical level of trainees.During the post-study training period, we divided the trainees into groups and went to different post-up bases for one-to-one training. The exchanges were regularly exchanged with the post.Through the exchange of departmental counterparts, observation of high-quality learning courses, and middle-level cadre's experience sharing, the purpose of upgrading the middle management cadre's work skills is achieved. Finally, the project team also arranged for the participants to summarize the exchange meeting so that the trainees could digest and absorb the training content. The participation rate of the entire training trainee reached more than $90 \%$. Rich and varied forms of training enhance the attractiveness and appeal of training, maximizing training effectiveness.

\section{Improve the Quality Assessment System, Attach Importance to Trainees' Feedback and Post-training Guidance}

\section{Track and Guide the Students after Training}

The project team should actively use network resources to implement follow-up training for trainees. Including training class QQ group, WeChat group, group space and other permanent reservations, easy to share quality resources and successful experience. According to different grades and types of project requirements, online training courses can be customized for trainees. After the completion of concentrated face-to-face training, trainees are free to choose time to complete the online courses and strengthen the training results. For example, Changshu Institute of Technology has established long-term cooperation with a number of professional teacher education network training units, such as Beijing Education Network Education Technology Development Co., Ltd. and the National Academy of Education Administration Distance Training Center. Each year, tailor-made online courses for "national training project" students. After the completion of the centralized training, the trainees can complete the online course study within 3 months, and receive the online course credits certificate when they complete the required academic hours. The post-training online training courses we provided to students strengthened the training results and received a good reputation. 


\section{Complete self-evaluation of Training in Time}

After the training, the base must strictly complete the quality assessment of the project. The questionnaire of student satisfaction as an important part of the quality assessment should reflect the overall satisfaction of the trainee, training goal setting and positioning, training courses and activities. Training resources, training methods and method selection, training expert level, teaching facilities and conditions, food and accommodation conditions and service quality, project management team service attitude and quality, training results and harvest are the important reference materials for improving the quality of the base training. In addition, the project team should carefully complete the self-assessment summary and write a self-evaluation report. The self-evaluation report should include basic project overview, implementation process management, training effectiveness display, training fund usage, experience and reflection, etc., and comprehensive and meticulously review and organize the training.

\section{Conclusion}

Raising the level of project management in the teacher training base has a bearing on the quality of teacher training and affects the development of the teaching staff and the improvement of the quality of teachers. Every base that undertakes teacher training should think about how to innovate and reform training methods, how to enhance the pertinence and effectiveness of teacher training, and how to improve the quality of work. Therefore, the teacher training base must constantly update the concept of teacher training, understand the frontiers of teacher training trends and policies, learn and master the training skills, improve the working methods, and make teacher training work solid, fine and excellent.

\section{References}

[1] Liu Xiao. Reflections on Strengthening the Professional Construction of Teachers' Training Institutions. Continue Education Research, August 2011.

[2] Wu Xuejun. Study on the Training Model of Primary and Secondary School Teachers. Journal of Kaifeng Institute of Education, November 2017

[3] Zhang Yixian. Several Thoughts on Practicing the Theory of Objective Management in the Training of Primary and Secondary School Teachers' Training. Journal of Fujian Institute of Education, April 2016. 